\title{
SPECIFIC OPPORTUNITIES THROUGH CAD SySTEMS FOR PROFILING A REAL INVOLUTE CURVES OF A SPUR GEAR
}

\section{YULIYAN DIMITROV \& KRASIMIR KAMENOV}

Abstract: Due to the application in practice and in the process of training students in engineering specialties, it is very important to analyze the possibilities of profiling real involute curves of spure gears. The report presents specific ones opportunities to build a real involute curves of a spure gear through one of the most used CAD systems. The results of the application of the AutoCAD.NET API developed by the authors for the simulation of the profile of cylindrical spur gears with external teeth are presented. The report is presented a comparative analysis between involute profiles built from existing CAD systems and profiles built through the developed application by the authors. The results of the research identified many possibilities for using the developed application for the educational process of students and for use in real specific production of gears obtained through the technologies of direct cutting of the contours of the gears by laser, plasma and water jet cutting.

Key words: involute, gear, .NET API, CAD system
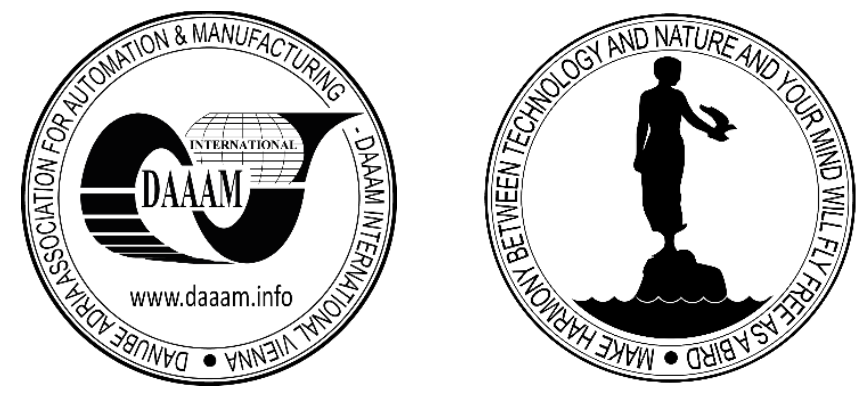

Authors' data: Dimitrov, Y[uliyan]; Kamenov, K[rasimir], University of Ruse, Studentska 8 str, 7000 Ruse, BG, ydimitrov@uni-ruse.bg

This Publication has to be referred as: Dimitrov, Y[uliyan] \& Kamenov, K[rasimir] (2019). Specific Opportunities Through CAD Systems for Profiling a Real Involute Curves of a Spur Gear, Chapter 19 in DAAAM International Scientific Book 2019, pp.241-250, B. Katalinic (Ed.), Published by DAAAM International, ISBN 978-3902734-24-2, ISSN 1726-9687, Vienna, Austria

DOI: $10.2507 /$ daaam.scibook.2019.19 
Dimitrov, Y.\& Kamenov, K.: Specific Opportunities Through CAD Systems for Pr...

\section{Introduction}

With the development of spur gear manufacturing technologies, in addition to the traditional method of cutting gears using mechanically cutting tools, new methods are being used. These are the cutting of spur gears of metal and non-metal sheet blanks of machines for laser, plasma and water jet cutting. The quality of the parts obtained depends not only on the precision of the machine and the technology, but also on the precise setting of the involuntary contour of the teeth for cutting included in the CNC cutting program [6],[7],[8],[9].

Under certain conditions (irresponsible low precision gears, slow gears, kinematic gears, low loading gears, non-metallic toy gears, demonstration and training gears, etc.), it is financially appropriate to use these technologies. This determines the importance of building a real involute profile of the CAD systems used by the engineers.

The need for the study is due to the fact that 3D CAD systems (SW Simulation, Autodesk Inventor and others) require the 3D model of the gears to be prepared in advance, after which a 2D contour of the gear wheel is generated from this 3D model. With one of the most widely used 2D Autodesk Autocad programs, the involute curve must be manually profiled, which is a very complex and extended process. For this reason, 3D programs are mainly used to automatically generate 3D models of gears, then the $2 \mathrm{D}$ contour of the gear is extracted.

One of the most used features of 3D programs is engineering simulations to study the elements when loading 3D models of gears, and the reality of the results of these simulations depends a lot on the accuracy of profiling the 3D model of the spur gear. Some of the most used 3D CAD programs, such as SolidWorks and Autodesk Inventor ${ }^{\circledR}$, do not produce a real tooth contour profile in the generation of gears, but only a curved curve to simplify the file.

For this purpose, it is necessary to first generates the corect geometrically involuntary profile of the whole wheel teeth, and then by means of three-dimensional operations to design the model and then to import it into the simulation systems.

\section{The results of profiling a involute curves of a spur gear wheel through CAD systems}

The results of the work of the two most used CAD systems in Bulgaria SolidWorks and Autosdesk Inventor - are analyzed. Spur gear profiles were generated with these two systems for different variants of the m-module and z-number of teeth parameters. The aim is to obtain and analyze the contours of one of the most commonly used gears (Table 1). Which of these contours is closest to a real involuntary contour?

\begin{tabular}{|l|l|l|l|}
\hline Module, $\mathrm{m}[\mathrm{mm}]$ & 3 & 5 & 9 \\
\hline Number of teeth, $\mathrm{z}_{1}$ & 20 & 20 & 20 \\
\hline Number of teeth, $\mathrm{z}_{2}$ & 60 & 60 & 60 \\
\hline
\end{tabular}

Tab. 1. Variants of spur gear parameters for research 
With the Autosdesk Inventor program, can be generated from the Design/Spur Gear menu 3D models of spur gears. From the models thus obtained, can be generated a simplified version (Export to DWG) of the involute tooth curve (fig.1). The curve thus obtained is visually approximated but does not correspond to the real curve.

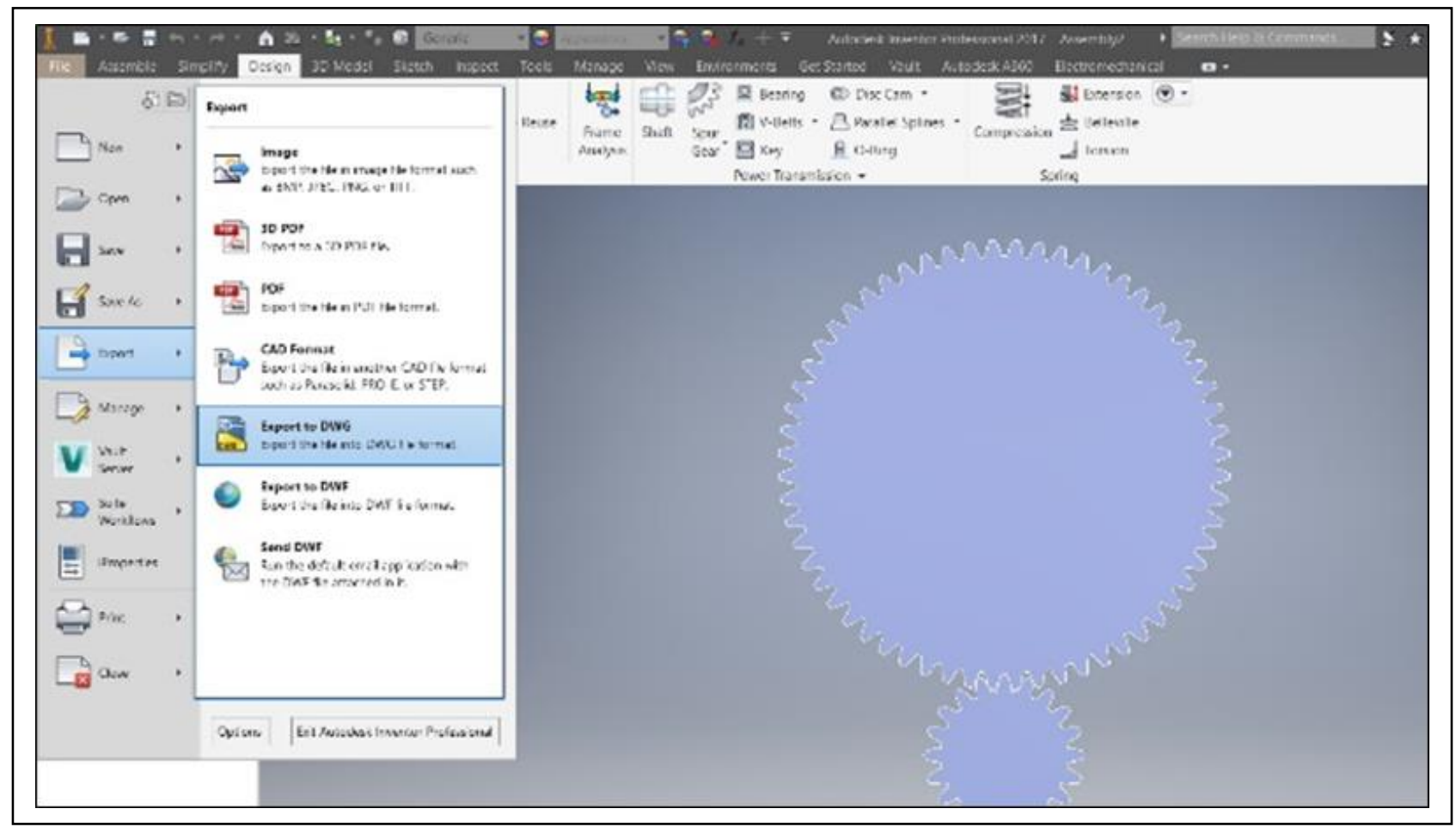

Fig. 1. Generation of a simplified involute curve with Autodesk Inventor

The command "Export tooth shape" (fig.2a) is used to generate the real involute curve more precisely. In this way, the involuntary contour of a single tooth is exporting it to a .dwg file (fig.2b). It is then necessary to process further to obtain the contours of all the teeth.

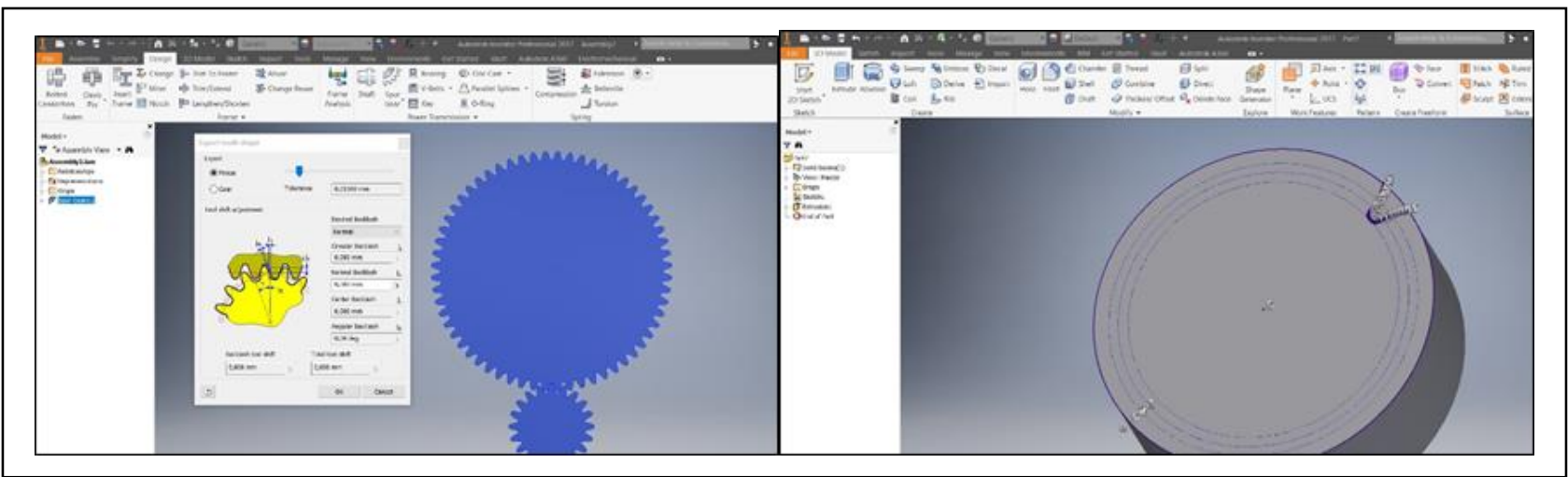

Fig. 2. A working view of Autosdesk Inventor CAD system

The part of results of profiling a real and simplified involute tooth contour of spur gear for the selected variants through the Autosdesk Inventory are shown in fig.3 
Dimitrov, Y.\& Kamenov, K.: Specific Opportunities Through CAD Systems for Pr...

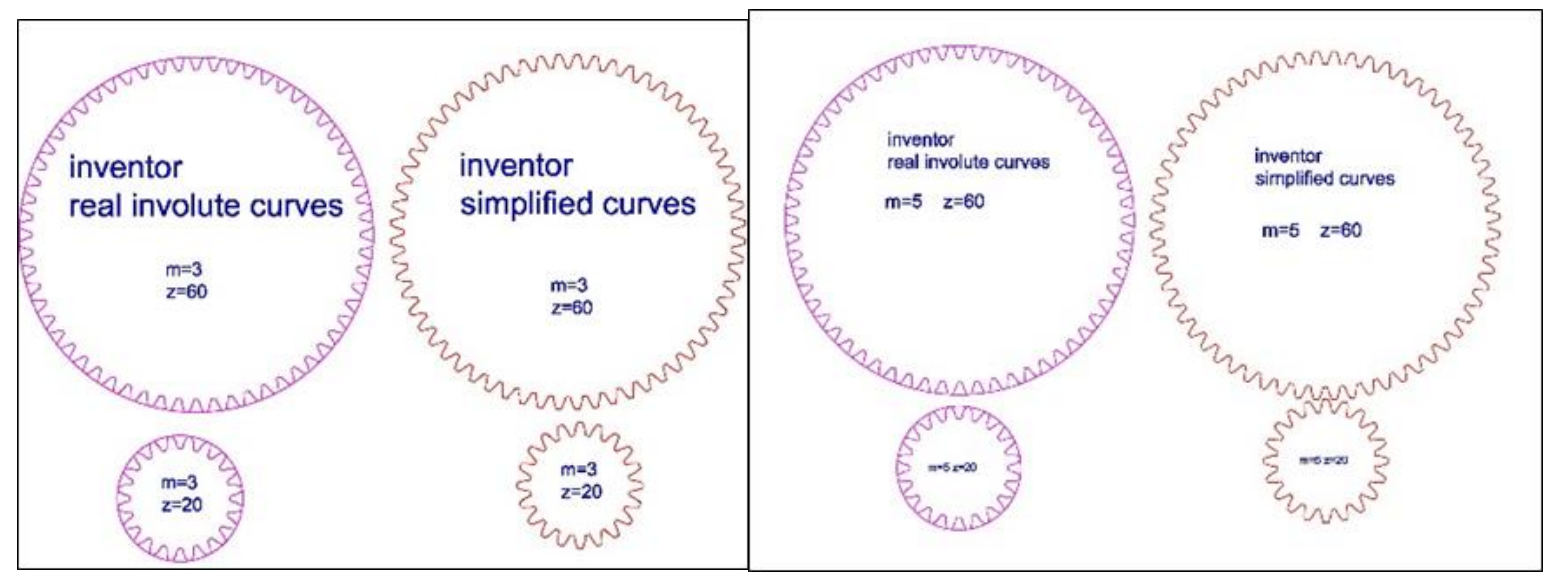

Fig. 3. Results of profiling a involuntary contour of a spur gear teeth with Autosdesk Inventor

The second basic program that can be used to generate a involuntary contour is the SolidWorks CAD program. Through it from the Toolbox /... .Standart... / Power transmission menu can be generated 3D models of gears in the similarity of Inventory, but with less possibilities for working with different parameters. After the 3D models are generated, the involute contours are exported to a .dwg or .dxf file.

\section{Application AutoCAD .NET API for spur gear profiling}

The largest application among engineering 2D programs is Autodesk Autocad, which does not, however, have an automatic module for generating the involute profile. This can be done using the existing methodology in Machine Desing by building it manually. This is a process with many calculations and manual drawing operations. One of the advantages and an important reason for the widespread distribution of Autocad 2D is the file format (DXF and DWG) that all other CAD/CAM software vendors use to transfer data from one system to another. This versatility enables subsequent processing to be accomplished through differing software products [10],[11].

The report presents the work and results of the AutoCAD .NET API for spur gear profiling application to build an involuntary spur gear profile. The application was developed by the authors of the report. The result of the application generates in 2D plane the profile of the contour of the gear. The application uses the Application Programming Interface (API) of AutoCAD .NET, which allows you to manipulate AutoCAD and drawing files through a large set of libraries [3],[4].

The application works with logical functions and geometric objects. The use of logic functions on geometric objects is very similar to the practical method of cutting gears by gear shaping. The profile is designed to meet all the requirements and features of the output tool profile. This method of synthesis of an involute profile can be attributed to geometric methods of profiling based on the rolling two gears. The result of the application is a .dwg file that generates the contours of the two gears [1],[2]. 


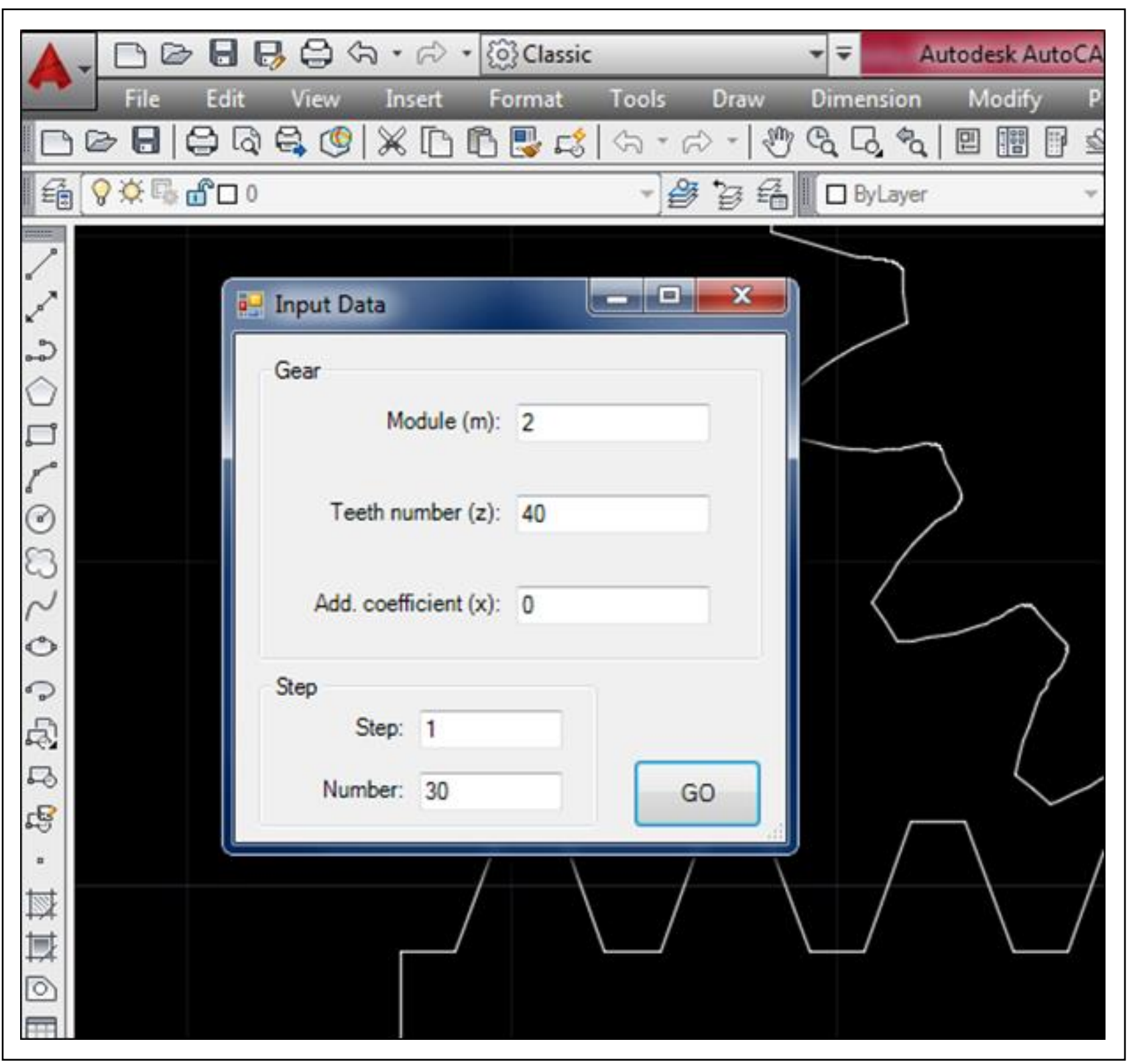

Fig. 4. A working view of the AutoCAD .NET API for spur gear profiling

In Fig. 4 shows the desktop window for entering the input data required for the geometric construction of the profile of an involute spure gear: module (m), number of teeth $(\mathrm{z})$ and coefficient of correction $(\mathrm{x})$.

To reduce the likelihood of an accidental error in the data input, a special algorithm checks their accuracy. Only then does the process of calculations (GO button), which first calculates the parameters of the output contour of the tool- rack, and then of the workpiece of the gear.

\section{Tables and Figures}

In order to check the correctness of each involuntary contour, a comparative analysis is made between all generated contours from Autodesk Inventor, SolidWorks and Application AutoCAD .NET API for spur gear profiling by overlaying each other. All results are generated in .dwg files, which in the Autocad environment are overlaid into a single file. 
Dimitrov, Y.\& Kamenov, K.: Specific Opportunities Through CAD Systems for Pr...

Basic contour is accepted the generated contour from the AutoCAD .NET API for spur gear profiling, because this contour is obtained by copying the process of cutting a real spur gear according to actual dentition by standards and methodologies in the Mashine design technical literature [12].

\begin{tabular}{|l|l|}
\hline CAD Program & Color \\
\hline Autodesk Inventor simplified curves & \\
\hline Autodesk Inventor real involute curves & \\
\hline SolidWorks & \\
\hline AutoCAD .NET API for spur gear profiling, & \\
\hline
\end{tabular}

Tab. 2. Colors used for the curves of the individual programs

The analysis compares contours with small, medium and large modules and a small and large number of teeth. The purpose is to check whether the modification of the module and the number of teeth affect the accuracy of contour generation under different programs.

Table 2 shows the different colors used for different contours for better visualization. After overlaying all the contours in one file, the following results are shown in Fig.5

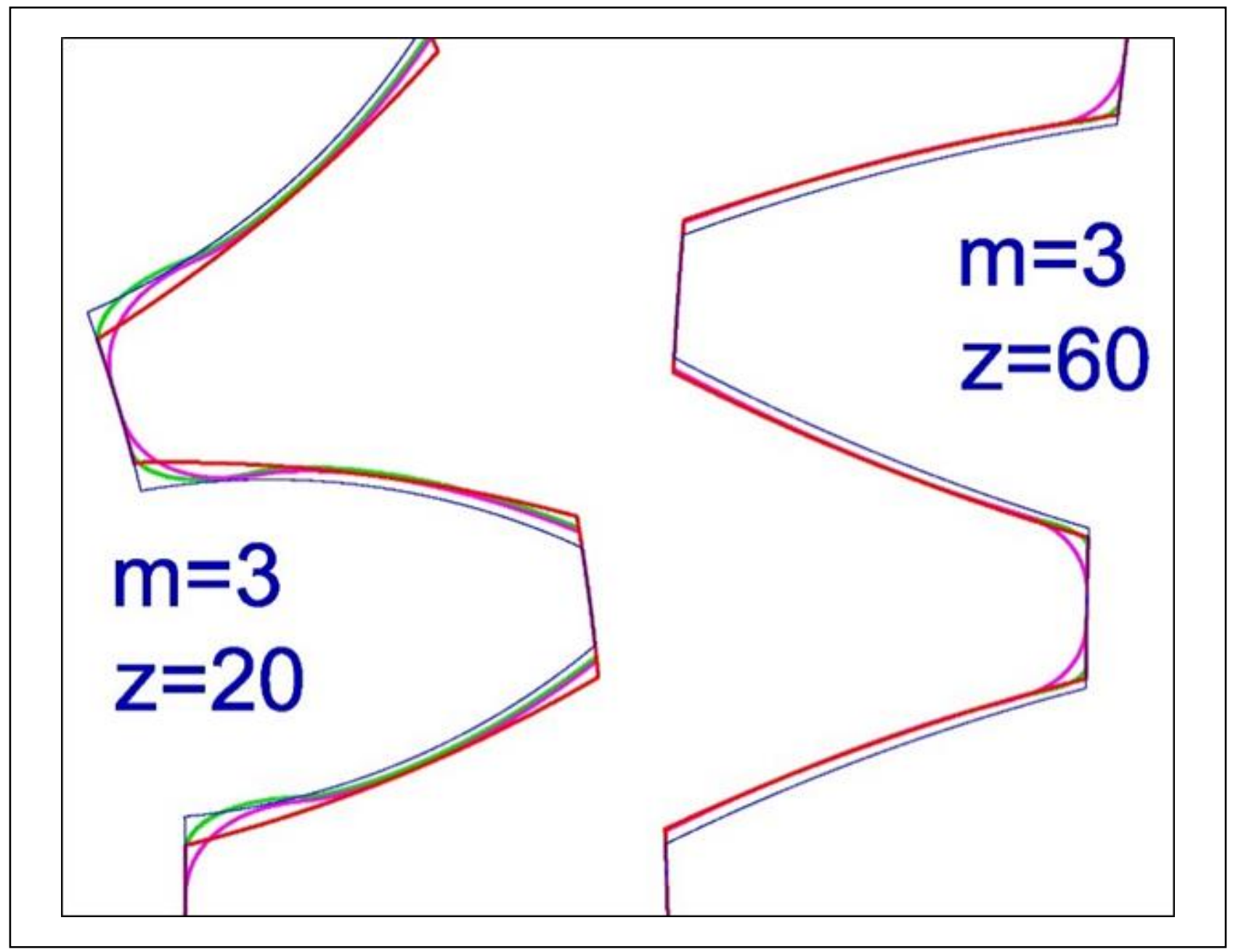

Fig. 5a. Overlay all curves with $\mathrm{m}=3 \mathrm{~mm}$ 


\section{\begin{tabular}{lll}
\hline DAAAM INTERNATIONAL SCIENTIFIC BOOK 2019 & pp. 241-250 & Chapter 19 \\
\hline
\end{tabular}}

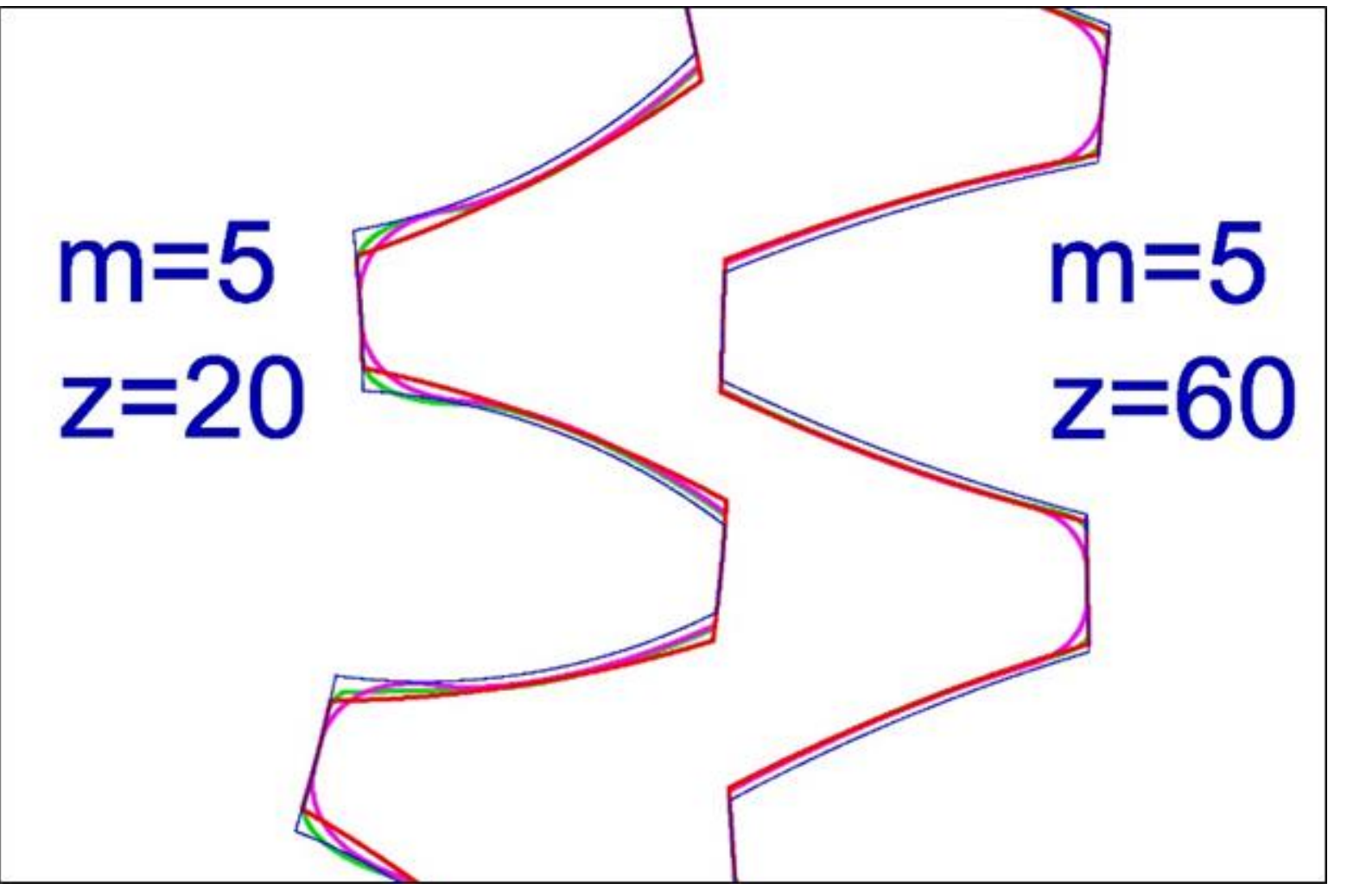

Fig. 5b. Overlay all curves with $\mathrm{m}=5 \mathrm{~mm}$

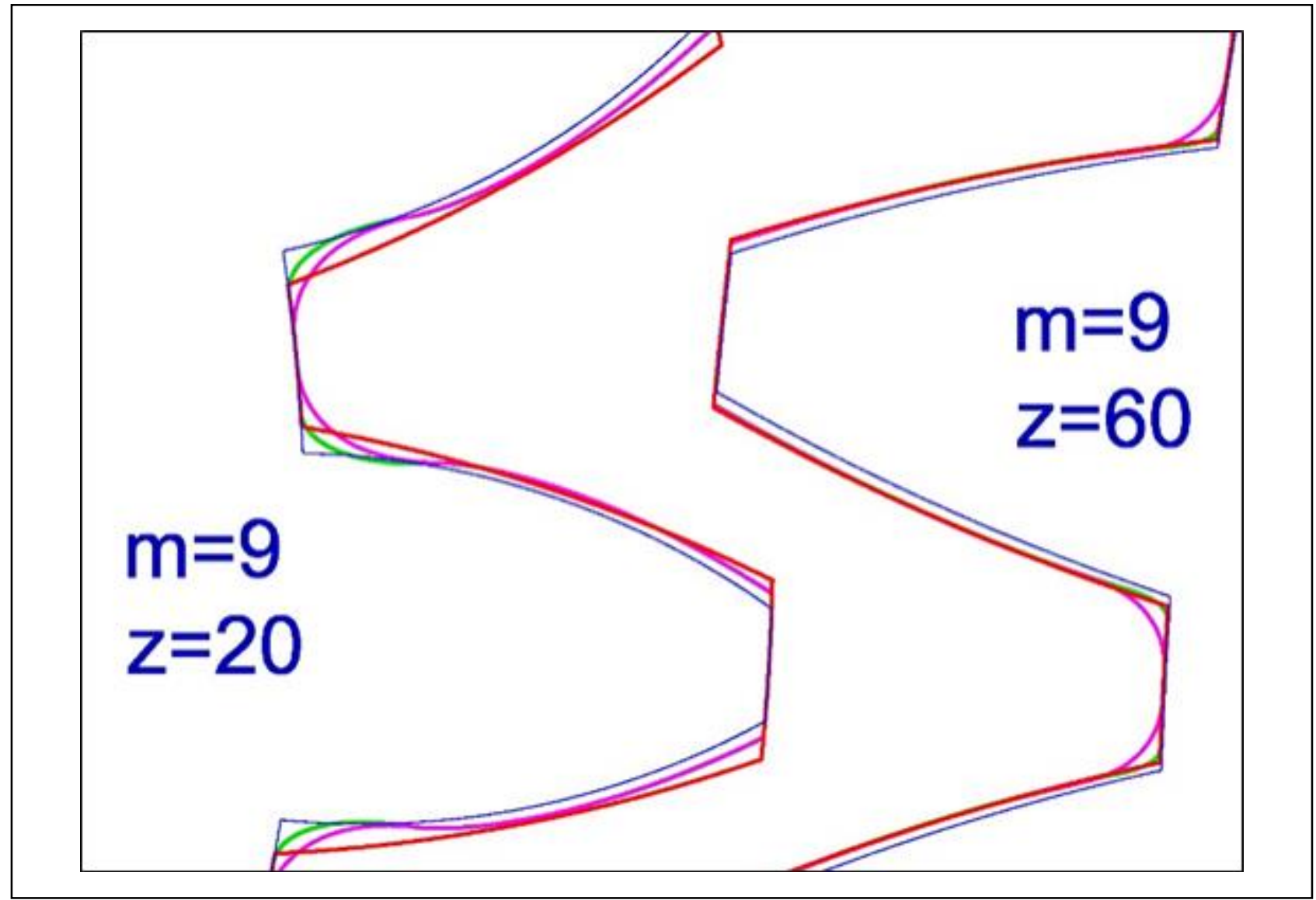

Fig. 5c. Overlay all curves with $\mathrm{m}=9 \mathrm{~mm}$ 
- The gear teeth generated by the SolidWorks program (blue line) are less thick with all the modules and the number of teeth, the difference is up to $0.5 \mathrm{~mm}$. The transition curve at the base of the tooth does not have a fillet, which is unacceptable for a real spur gear. The diameters correspond to the other curves.

- The gear teeth generated by the Autodesk Inventor program as a simplified curve (red line) for all modules but with a small number of teeth deviate up to $0.5 \mathrm{~mm}$ from the accepted contour. Gears with a large number of teeth do not show much deviation. The transition curve at the base of the tooth does not have a fillet, which is unacceptable for a real spur gear. The diameters correspond to the other curves.

- The gear teeth generated by the Autodesk Inventor program as a real curve (purple line) for all modules and number of teeth do not deviate from the accepted contour. The transition curve at the base of the tooth has a fillet larger than the base. The diameters correspond to the other curves.

The analysis reveals that the SolidWorks program does not generate a real contour of a spur gear, the curves generated are for visualization only and are not for practical use. The Autodesk Inventor program offers two options for visualizing the involute curves - simplified to make it easier to work with the program and, if necessary, a relatively accurate and realistic contour.

The problem is that the program generates only one tooth, which means performing more operations through another module of the program to generate the entire contour of the gear. This prolongs and complicates the work. While using the AutoCAD .NET API for spur gear profiling and the much lighter and less expensive Autodesk Autocad engineering program, it is very easy and quick to create and use a real such profile.

\section{Conclusion}

Using AutoCAD's .NET API application to solve practical, learning, and scientific tasks gives developers, scientists, and engineers great opportunities to practice. The application offers an easy and fast solution to the task of building an accurate profile of an involuntary spur gear in AutoCAD.

The resulting profile can be used to create a 3D model of a spur gear that is subjected to strength and dynamic testing in other software systems based on the finite element method. The resulting involute curves of the designed spur gears through the indicated application are very accurate to the real involute, while the constructed involutes through the considered CAD systems in the analysis have deviations. The comparative analysis shows the good results of gearing profiling through the created application of AutoCAD .NET API. 
The application can be used to illustrate the learning process when studying involuntary gearing. It allows you to show and simulate the conditions undercuting occurs. It is very well seen after a suitable enlargement of the shape of the transition curve and the change, and with various bevels and fillets at the tip of the teeth of the rack.

From the obtained profiles different strength simulations can be made or spur gear can be cut on laser, plasma or water jet cutting machines with sufficient accuracy of the tooth profile.

The future task of the report's autorrs, derived from the results obtained, is to make this application generate profile curves for gears with internal engagement.

\section{Acknowledgements}

This paper would not be possible without the assistance of my colleagues from the department and the assistance of the private companies with which the Department of Mechanical Engineering, Machine Elements, Engineering Graphics and Physics in University of Ruse.

The study was supported by contract of University of Ruse "Angel Kanchev", № BG05M2OP001-2.009-0011-C01, " Support for the development of human resources for research and innovation at the University of Ruse "Angel Kanchev". The project is funded with support from the Operational Program " Science and Education for Smart Growth 2014 - 2020" financed by the European Social Fund of the European Union.

\section{References}

Kamenov, K. (2017). Precise modeling of the involute gear for external gear teeth in AutoCAD environment, 56-th Science Conference of Ruse University, ISSN 13113321

Kamenov, K. \& Dimitrov, Y. (2019). Application of Autocad .NET API for simulation of cylindrical gears profiling 6th International BAPT Conference - Power transmissions 2019, ISSN 978-619-7383-12-6

Pascu ,N. \& Tiberiu, D. (2016) Graphic modeling and visual impact on the structural design of packaging in CAD applications, Proceedings of the 26th DAAAM International Symposium, pp.0265-0270, ISSN 1726-9679

Pascu, N. \& Tiberiu, D. (2013). Realistic Scenes in CAD Application, 24th DAAAM International Symposium on Intelligent Manufacturing and Automation 2013

Gheorge, O. \& Ionut, G. (2016). Embedded modelling and simulation software system for adaptive engineering of hydraulic gear pumps, Proceedings of the 26th DAAAM International Symposium, pp.0311-0319, ISSN 1726-9679 
Dimitrov, Y.\& Kamenov, K.: Specific Opportunities Through CAD Systems for Pr...

Kroupa, T. \& Dana, M. (2017). Abrasive waterjet cutting, Proceedings of the 28th DAAAM International Symposium, pp.0493-0499, ISSN 1726-9679

Krajcars, D. (2013). Comparison Metal Water Jet Cutting with Laser and Plasma Cutting, 24th DAAAM International Symposium on Intelligent Manufacturing and Automation 2013

Muhamedagic, K. \& Begic-Hajdarevic, D. (2017). Multi-response optimization of plasma cutting parameters using grey relational analysis, Proceedings of the 28th DAAAM International Symposium, pp.1074-1082, ISSN 1726-9679,

Zetkova, I. \& Jenicek, S. (2018). Influences of cutting process parameters on the cutting quality when water jet cutting, Proceedings of the 29th DAAAM International Symposium, pp.1286-1292, ISSN 1726-9679

AUTODESK Knowledge Network (2017), https://knowledge.autodesk.com/

Managed .NET Developer's Guide (.NET) (2017), https://knowledge.autodesk.com/searchresult/caas/CloudHelp/cloudhelp/2017/ENU/ AutoCAD-NET/files/GUID-C3F3C736-40CF-44A0-9210-55F6A939B6F2-htm.html Juvinall, R. \& Marshek, K. (2012). Fundamentals of Machine Component Design fifth edition, John Wiley \& Sons Inc, ISBN -13 9781118012895 